\title{
Synthesis and Characterization of Silver Nanoparticles
}

\section{Using Alginate from the Brown Seaweed Laminaria} ochroleuca: Structural Features and Antibacterial Activity

\author{
Soukaina Kaidi ${ }^{1(\mathbb{D})}$, Zahira Belattmania ${ }^{1, *}{ }^{(\mathbb{D})}$, Fouad Bentiss ${ }^{2,3}(\mathbb{D})$, Charafeddine Jama ${ }^{3(\mathbb{D})}$, \\ Abdeltif Reani ${ }^{1}$ (D), Brahim Sabour ${ }^{1}$ (D) \\ 1 Phycology, Blue Biodiversity \& Biotechnology RU —P3B, Laboratory of Plant Biotechnology, Ecology and Ecosystem \\ Valorization, Faculty of Sciences, Chouaib Doukkali University, P.O. Box 20, El Jadida M-24000, Morocco; \\ souk.kaidi@gmail.com (S.K); belattmania.z@ucd.ac.ma (Z.B.); abreani@yahoo.fr (A.R.); sabour.b@ucd.ac.ma (B.S.); \\ 2 Laboratory of Catalysis and Corrosion of Materials, Faculty of Sciences, Chouaib Doukkali University, P.O. Box 20, El \\ Jadida M-24000, Morocco; fbentiss@gmail.com (F.B.); \\ 3 University of Lille, CNRS, INRAE, Centrale Lille, UMR 8207, UMET-Unité Matériaux et Transformations, F-59000 \\ Lille, France; charafeddine.jama@centralelille.fr (C.J.); \\ * Correspondence: belattmania.z@ucd.ac.ma (Z.B.);
}

Scopus Author ID 56676284700

Received: 29.07.2021; Revised: 22.09.2021; Accepted: 25.09.2021; Published: 4.11.2021

\begin{abstract}
In this study, inexpensive and eco-friendly production of the silver nanoparticles (AgNPs) was explored using Laminaria ochroleuca sodium alginate as stabilizing and reducing agent. The synthesized nanoparticles were characterized by various analytical techniques such as UV-Vis spectroscopy, Energy dispersive X-ray spectrometer (EDX), X-ray diffraction (XRD), transmission electron microscopy (TEM), TEM selected area electron diffraction (SAED), Fourier transform infrared (FTIR) spectroscopy, and thermogravimetric analysis (TGA). The synthesis of AgNPs was elucidated by characteristic absorption peaks in the UV-Vis test. The FTIR analysis revealed the involvement of many functional groups in the bioreduction and the stabilization of AgNPs, while TEM images illustrated the spherical shape with maximum particles found in the size range of 10-20 nm. Prominent peaks and silver diffraction rings shown by the XRD spectrum and SAED pattern, respectively, confirmed the crystalline nature (fcc) of the synthesized AgNPs, which were found to be thermally stable based on TGA analysis. The AgNPs exhibited strong antibacterial activity against Gram+ and Gram- bacteria. The synthesized silver nanoparticles using Laminaria ochroleuca sodium alginate revealed interesting properties that could be potentially used for pharmaceutical applications.
\end{abstract}

Keywords: silver nanoparticles; biosynthesis; sodium alginate; Laminaria ochroleuca.

(C) 2021 by the authors. This article is an open-access article distributed under the terms and conditions of the Creative Commons Attribution (CC BY) license (https://creativecommons.org/licenses/by/4.0/).

\section{Introduction}

Nanotechnology has progressively more expanded as a promising field of applied science due to its various applications, which involve many aspects of human life using nanoparticles [1-3]. Research on nanomaterials mainly emphasizes the synthesis of nanoparticles of various sizes, shapes, and structures for desired applications [4]. Among the various nanoparticles, silver nanoparticles have established more interest due to their properties such as size, shape, antimicrobial and antioxidant activity [5]. Because of their distinguishing physico-chemical attributes [6], silver nanoparticles (AgNPs) are now one of the inorganic noble metal nanoparticles that have potential application in the areas of chemistry, physics, 
environmental remediation, optoelectronics, material science, biomedical devices, and renewable energies [7].

Several methods have been explored for the synthesis and stabilization of AgNPs. However, many of them were proved to have adverse effects in applications with potential environmental toxicity, as well as biological risks [8]. Hence, biological methods were established as a valuable, inexpensive, and less cumbersome alternative.

Currently, there is increasing attention to the synthesis of metal nanoparticles from marine sources [9]. The use of marine macroalgae in the biosynthesis of nanoparticles arises as an ecofriendly and thrilling approach [10]. By taking advantage of its biochemical properties, including its biocompatibility, biodegradability, immunogenicity, and non-toxicity in drug delivery system and cell encapsulation [11, 12], alginate from brown seaweeds is one of the various bio-molecules often used as an organic matrix to produce metallic nanoparticles [13-16].

In the present study, silver nanoparticles (AgNPs) were synthesized using sodium alginate extracted from the kelp Laminaria ochroleuca harvested from the Atlantic coast of Morocco. The characterization of the AgNPs was performed by UV-VIS spectroscopy, X-ray diffraction (XRD), Fourier transform infrared (FTIR) spectroscopy, transmission electron microscopy (TEM), TEM selected area electron diffraction (SAED), and thermogravimetric analysis (TGA). The synthesized AgNPs were tested for their antibacterial activity.

\section{Materials and Methods}

\subsection{Alginate extraction.}

Laminaria ochroleuca samples were collected from the Atlantic coast of Morocco (3314'47.5'N 8॰32'31.9' W). The kelp biomass was washed with water to remove impurities and dried in an oven at $50^{\circ} \mathrm{C}$. Dried samples were soaked in $2 \%$ formaldehyde for $24 \mathrm{~h}$ at room temperature, washed with distilled water, and added to $0.2 \mathrm{M} \mathrm{HCl}$ afterward for $24 \mathrm{~h}$, then washed again with distilled water before extraction using $2 \%$ sodium carbonate $\left(\mathrm{Na}_{2} \mathrm{CO}_{3}\right)$ during $24 \mathrm{~h}$. The soluble fraction was collected by centrifugation. The sodium alginate was precipitated by ethanol and washed by acetone, then dried at $50^{\circ} \mathrm{C}$.

\subsection{Synthesis of silver nanoparticles.}

Sodium alginate solution (1.5\%) extracted from Laminaria ochroleuca was added to $\mathrm{AgNO}_{3}(0.05 \mathrm{M})$ at a ratio $1: 1$. The mixture was stirred for $10 \mathrm{~min}$ at $60{ }^{\circ} \mathrm{C}$, and then incubated at room temperature in the dark for $2 \mathrm{~h}$. After the centrifugation at $5000 \mathrm{rpm}$ for $45 \mathrm{~min}$ and the precipitation, the product was dried at $40{ }^{\circ} \mathrm{C}$ to obtain the dry powder of the silver nanoparticles.

\subsection{Characterization of silver nanoparticles.}

UV-Vis spectrophotometer was performed to monitor the absorption pattern of synthesized silver nanoparticles using a spectrophotometer Metashe 5200 HPC. The samples were periodically recorded between 250 and $700 \mathrm{~nm}$. An energy-dispersive X-ray spectrometer (EDX) was used to determine the silver concentration of the synthesized nanoparticles (AgNPs). 
X-ray diffraction pattern of AgNPs was carried out on an XRD instrument operating at room temperature in a $2 \theta$ range of 0 to $70^{\circ}$ with a scan step width of $0.02^{\circ}$ using a D8 AdvanceBruker AXS diffractometer $(\mathrm{Cu} \mathrm{K} \alpha$ radiation, $\lambda=1.5418 \AA)$. The resulting XRD pattern profile was treated with the EVA program.

Transmission electron microscopy (TEM) was used to determine the size and shape of the synthesized silver nanoparticles. The analysis was performed using an FEI Tecnai G2 20 by suspending the nanoparticles in distilled water. After being homogenized, a drop was placed on a copper grid, then air-dried and observed in TEM. The crystalline nature of the silver nanoparticles was examined using the selected area electron diffraction (SAED) pattern.

FTIR spectroscopy analysis of biosynthesized AgNPs was performed with Thermo Scientific Nicolet IS50 FT-IR Spectrometer at room temperature over the wavenumber range 4000-400 cm-1 in an attenuated total reflectance (ATR) mode. A total of 64 scans were averaged for each sample at $4 \mathrm{~cm}-1$ resolution, and the IR spectra were then plotted and analyzed with the Omnic 9.1 software.

Thermogravimetric analysis (TGA) was performed using TGA Seteram 92. The TGA thermograms were recorded at a heating rate of $10{ }^{\circ} \mathrm{C}$ per min in the temperature range of $50{ }^{\circ} \mathrm{C}$ to $800{ }^{\circ} \mathrm{C}$ under a nitrogen atmosphere.

\subsection{Antibacterial activity.}

Antibacterial activity of the AgNPs was evaluated against different human pathogenic strains whose three Gram-negative bacteria Klebsiella pneumoniae (clinically isolated), Pseudomonas aeruginosa and Escherichia coli, and three Gram-positive bacteria Staphylococcus aureus, Bacillus cereus, and Micrococcus luteus using the technique of wells with a diameter of the beads of $6 \mathrm{~mm}$ [17]. In fact, $80 \mu \mathrm{L}$ of the synthesized AgNPs were deposited in wells formed on the Muller-Hinton agar medium previously inoculated with $0.1 \mathrm{~mL}$ of bacterial suspensions $\left(10^{6} \mathrm{CFU} / \mathrm{mL}\right)$ of the tested pathogenic microorganisms. The zones of inhibition that appeared around the wells after 18 hours of incubation at $37^{\circ} \mathrm{C}$ were subsequently measured [18].

\section{Results and Discussion}

\subsection{Synthesis of silver nanoparticles.}

When the extracted alginates solution is mixed with $\mathrm{AgNO}_{3}{ }^{-}$aqueous solution, the color of the reaction began immediately turn from colorless to yellowish and then to brownish. It has been reported that Ag-NPs solutions have brown coloration due to their characteristic excitation of surface plasmons in the range of 400-414 $\mathrm{nm}[19,20]$. The UV-Visible spectrum of the synthesized Ag-NPs (Figure 1) showed a prominent peak at $400 \mathrm{~nm}$. This peak is consigned to the excitation of surface plasmon resonance (SPR) and the reduction of $\mathrm{AgNO}_{3}$ for the thermodynamically favored formation of the AgNPs using sodium alginate [21, 22]. This heteropolysaccharide is a structural component of marine brown algae (Phaeophyceae)made up of linked $\beta$-D mannuronic acid (M) and $\alpha-\mathrm{L}$ guluronic acid $(\mathrm{G})$ residues and operates as a controller of nucleation, as well as a stabilizer due to its functional groups $(\mathrm{COOH}$ and $\mathrm{OH})$ with oxygen-rich structures. The latter binds strongly with nanoparticles via electrostatic interactions [23] due to the high charge density of the anionic sodium alginate that allows the replacement of sodium ions (existing in the sodium alginate structure) by the silver ions and contributes to the release of nitrate in the form of sodium nitrate 
[24]. This one-electron transfer from the carboxyl groups of alginates to the bound $\mathrm{Ag}^{+}$reduces the silver ion to $\mathrm{Ag}^{0}$ by dint of the hydroxyl groups provided by sodium alginate used as an organic matrix to produce metallic nanoparticles [25].

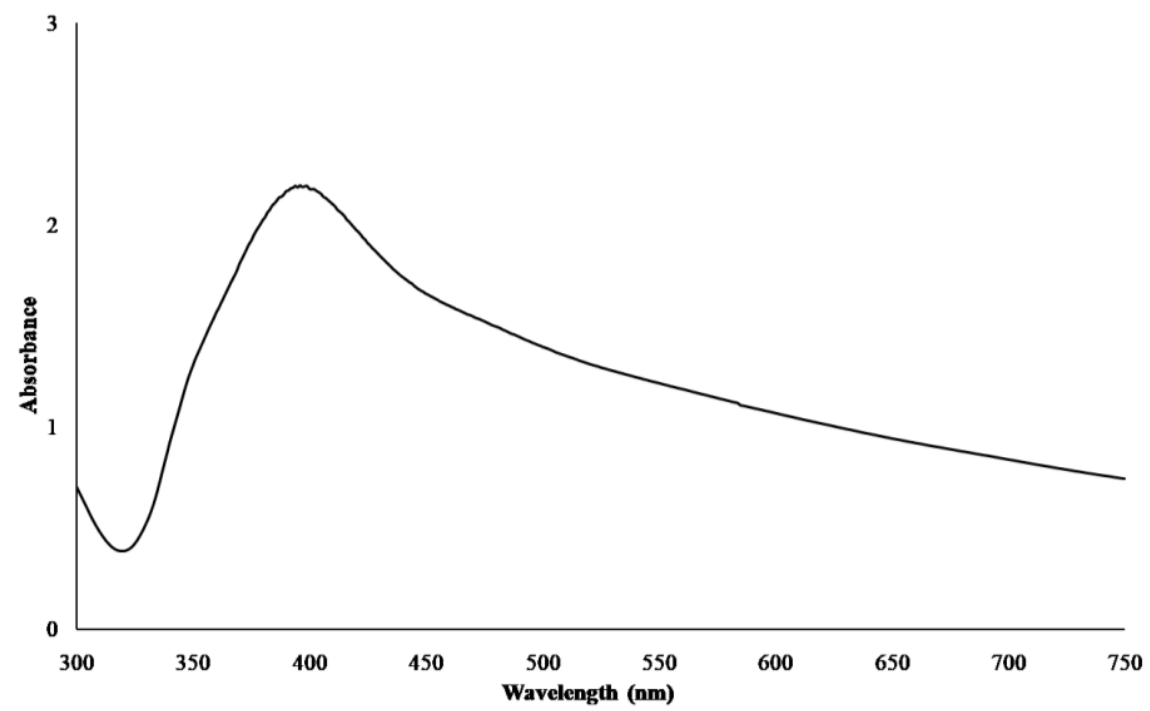

Figure 1. UV-Vis spectrum of AgNPs synthesized with Laminaria ochroleuca Na-alginate.

\subsection{TEM-SAED analysis.}

Transmission electron microscopy (TEM) images (Figure 2) clearly illustrate the homogeneity and spherical shape of the synthesized silver nanoparticles with predominant size in the range of 10-20 $\mathrm{nm}$ and a mean diameter of $14.89 \pm 6.1 \mathrm{~nm}$. It was reported that reducing and stabilizing agents strongly influence the metallic ion solution and incubation conditions the morphologies of the obtained nanoparticles $[25,26]$, being commonly quasi-spherical when produced for biopolymer particles [27, 28]. The obtained particle size is in accordance with previously reported green-synthesized AgNPs [29]. The TEM-SAED pattern revealed significant silver diffraction rings, suggesting the face cubic centered (fcc) crystalline nature of the AgNPs (Figure 3).

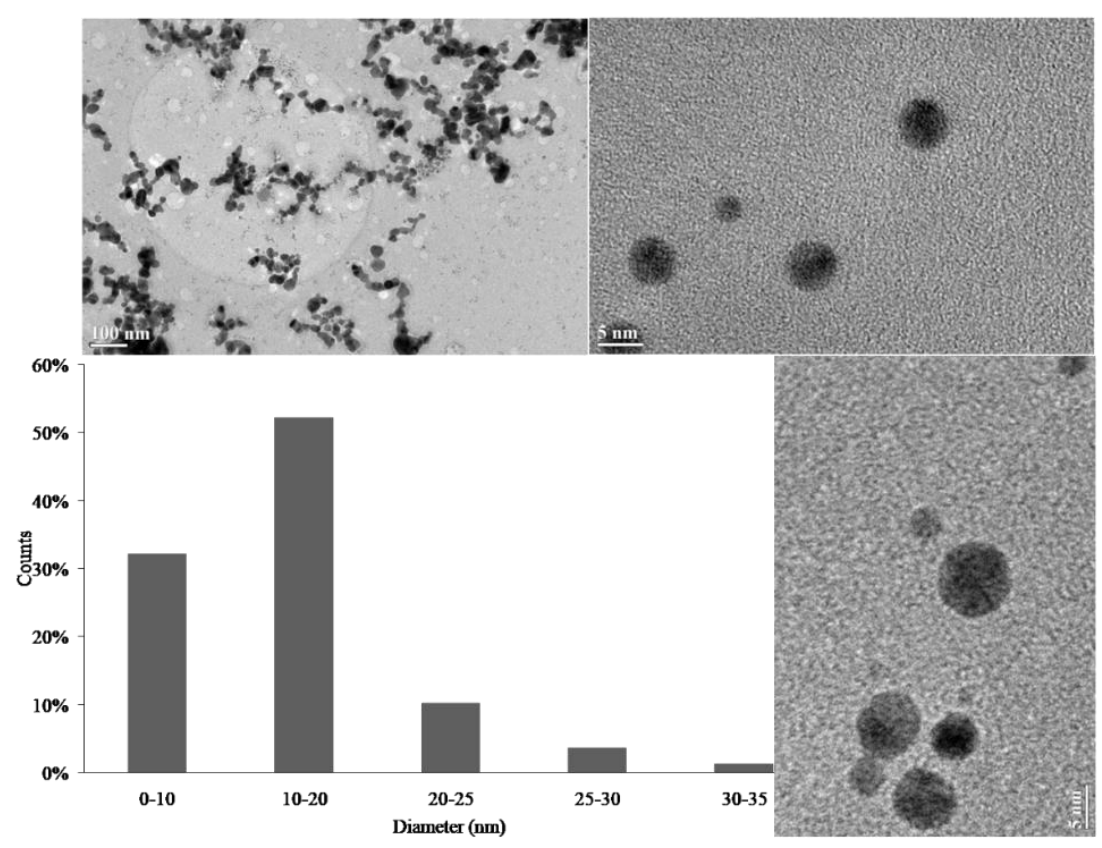

Figure 2. TEM micrographs and size distribution analysis of AgNPs synthesized with Laminaria ochroleuca Na-alginate. 


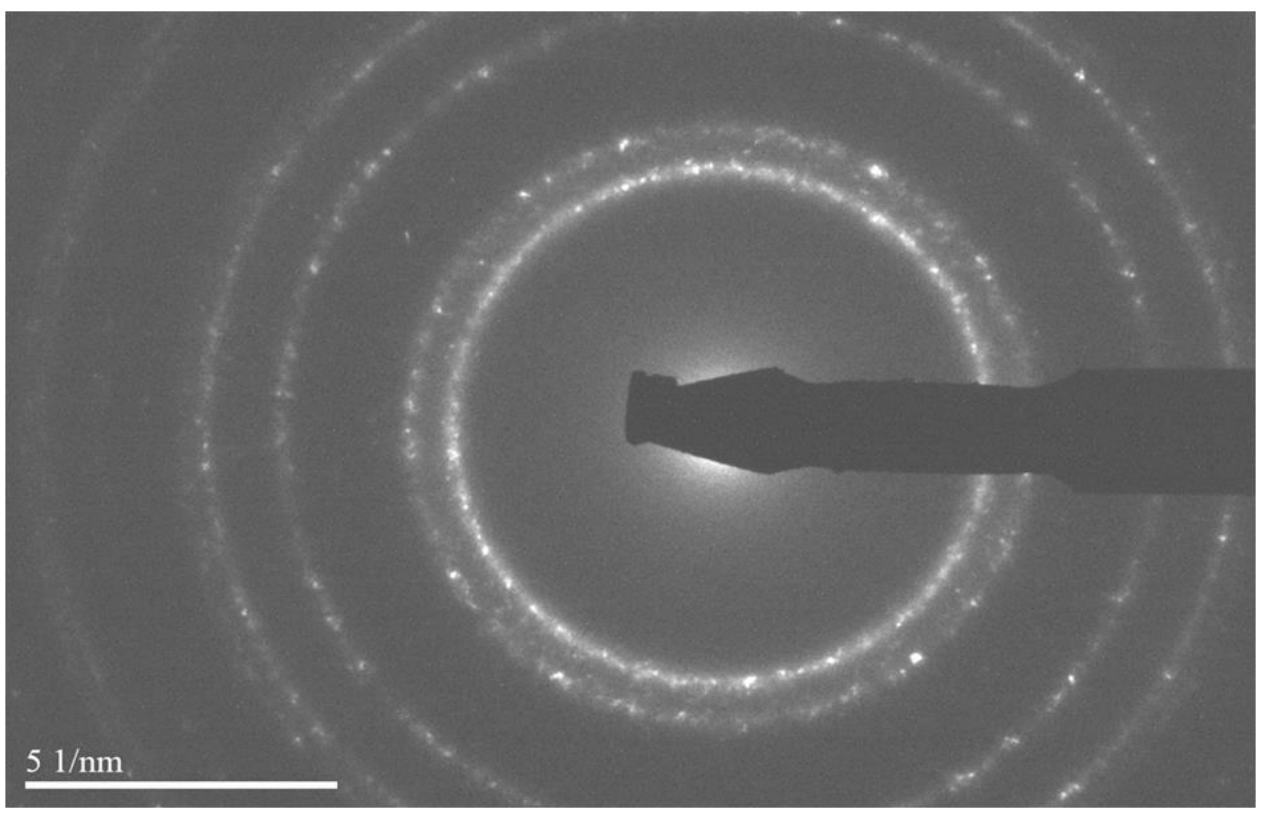

Figure 3. TEM-SAED ring pattern of the synthesized AgNPs.

\subsection{XRD analysis.}

The XRD pattern of the AgNPs (Figure 4) indicates four strong Bragg reflections exhibiting the characteristic peaks of the silver crystallites observed at $2 \theta$ values of $38.06^{\circ}$, $44.21^{\circ}$, and $64.43^{\circ}$ corresponding to the (111), (200) and (220) planes of silver crystals, respectively, indexed to the crystallographic planes of the face-centered cubic structure of silver (fcc) according to ICDD/ICSD from X'Pert High Score Plus (reference code: 01-0870719). XRD pattern clearly illustrates the crystalline structure of the synthesized AgNPs with fcc form. The weak diffraction peaks detected at $2 \theta$ values of $28^{\circ}, 29^{\circ}, 32.5^{\circ}$, and $34^{\circ}$ (Figure 4) can be assigned to Na-alginates due to the reflection of the (110) plane from polyguluronate unit, (200) plane from polymannuronate unit [30, 31]. This biopolymer used as an organic matrix to synthesize the silver nanoparticles is generally crystalline due to a strong interaction between chains through intermolecular hydrogen bonding [30].
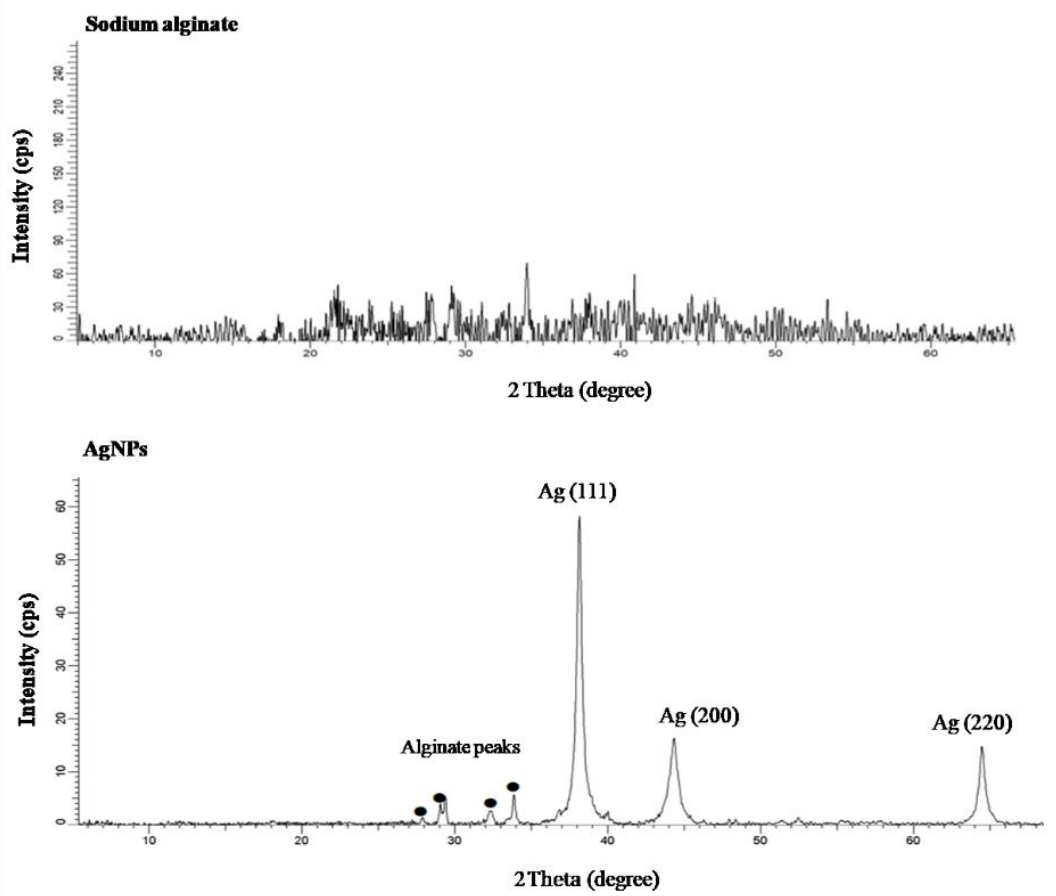

Figure 4. XRD spectra of Laminaria ochroleuca' Na-alginate and the synthesized AgNPs. 


\subsection{EDX Analysis.}

Energy-dispersive X-ray spectrometer (EDX) was employed to reveal the presence of silver nanoparticles and their elemental nature. As shown in Figure 5, the presence of elemental silver along with $\mathrm{Na}, \mathrm{O}, \mathrm{C}, \mathrm{Si}$, and $\mathrm{Cu}$ in the synthesized nanoparticles are confirmed by a prominent peak detected at $3 \mathrm{keV}$ linked to the typical absorption peak of AgNPs due to the surface plasma resonance (SPR) phenomenon [32].

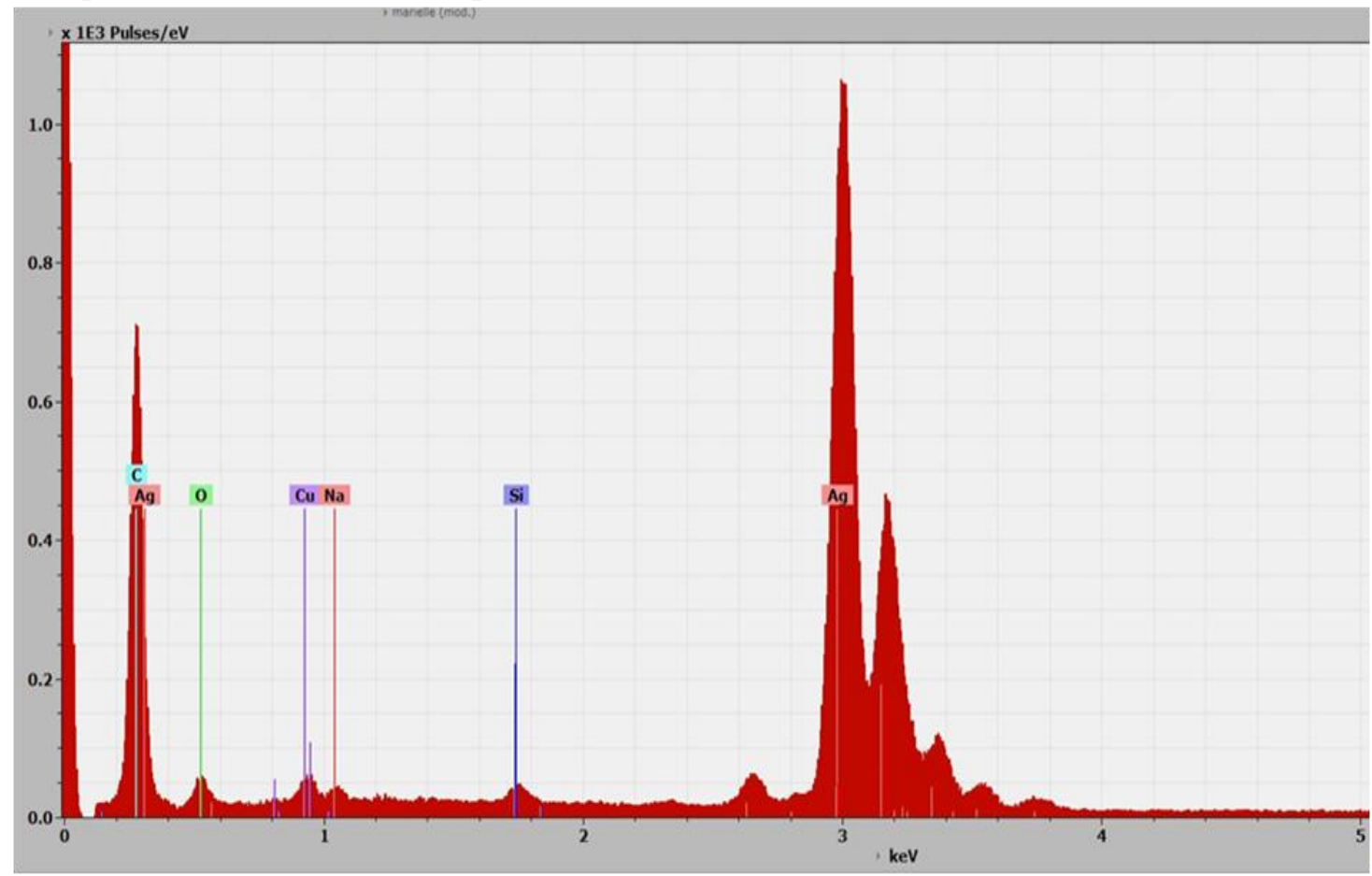

Figure 5. EDX spectrum of the synthesized AgNPs.

\subsection{FTIR Analysis.}

The FTIR spectra of Laminaria ochroleuca Na-alginate and synthesized AgNPs were performed in the range of 4000 to $500 \mathrm{~cm}^{-1}$, as shown in Figure 6. Broadband appeared at $3204.68 \mathrm{~cm}^{-1}$ could be assigned to the stretching vibration of $-\mathrm{OH}$ group [33]. The peak noted at $2919.75 \mathrm{~cm}^{-1}$ is related to carboxylate $\mathrm{O}=\mathrm{C}-\mathrm{O}$ asymmetric stretching vibrations $[34,35]$. According to Fenoradosoa et al. [36] and Leal et al. [37], the characteristic peak of alginate found at $1599.21 \mathrm{~cm}^{-1}$ can be attributed to asymmetric stretching vibrations of carboxylate salt ion. The strong peak at $1404.91 \mathrm{~cm}^{-1}$ may be assigned to $\mathrm{C}-\mathrm{OH}$ deformation vibration with the contribution of $\mathrm{O}-\mathrm{C}-\mathrm{O}$ symmetric stretching vibration of the carboxylate group, while the weak band at $1023 \mathrm{~cm}^{-1}$ may be assigned to $\mathrm{C}-\mathrm{O}$, and $\mathrm{C}-\mathrm{C}$ stretching vibrations of pyranose ring [38]. The following bands are important for the alginate characterization as they correspond to the anomeric region $\left(950\right.$ to $\left.750 \mathrm{~cm}^{-1}\right)$, in which two peaks were reported. The first one was observed at $877.95 \mathrm{~cm}^{-1}$ which corresponds to the $\mathrm{C} 1-\mathrm{H}$ deformation vibration of $\beta$-D-mannuronic acid residues. The second absorption brand band at $810,93 \mathrm{~cm}^{-1}$ was often reported for alginates, due to mannuronic acid residues [39]. Silver nanoparticles spectrum showed significant differences compared to that of Na-alginate (Figure 8). In fact, the band assigned to $\mathrm{O}-\mathrm{H}$ group in Na-alginate absorption region did not appear on the AgNPs spectrum while that attributed to $\mathrm{C}-\mathrm{OH}$ deformation shifted to $1329.22 \mathrm{~cm}^{-1}$. Similary, the peak assigned to $\mathrm{C}-\mathrm{O}$ and $\mathrm{C}-\mathrm{C}$ stretching vibrations of pyranose ring shifted to $978.71 \mathrm{~cm}^{-1}$. These results 
indicated that, hydroxyl and carboxylate groups could be involved in the synthesis of silver nanoparticles.

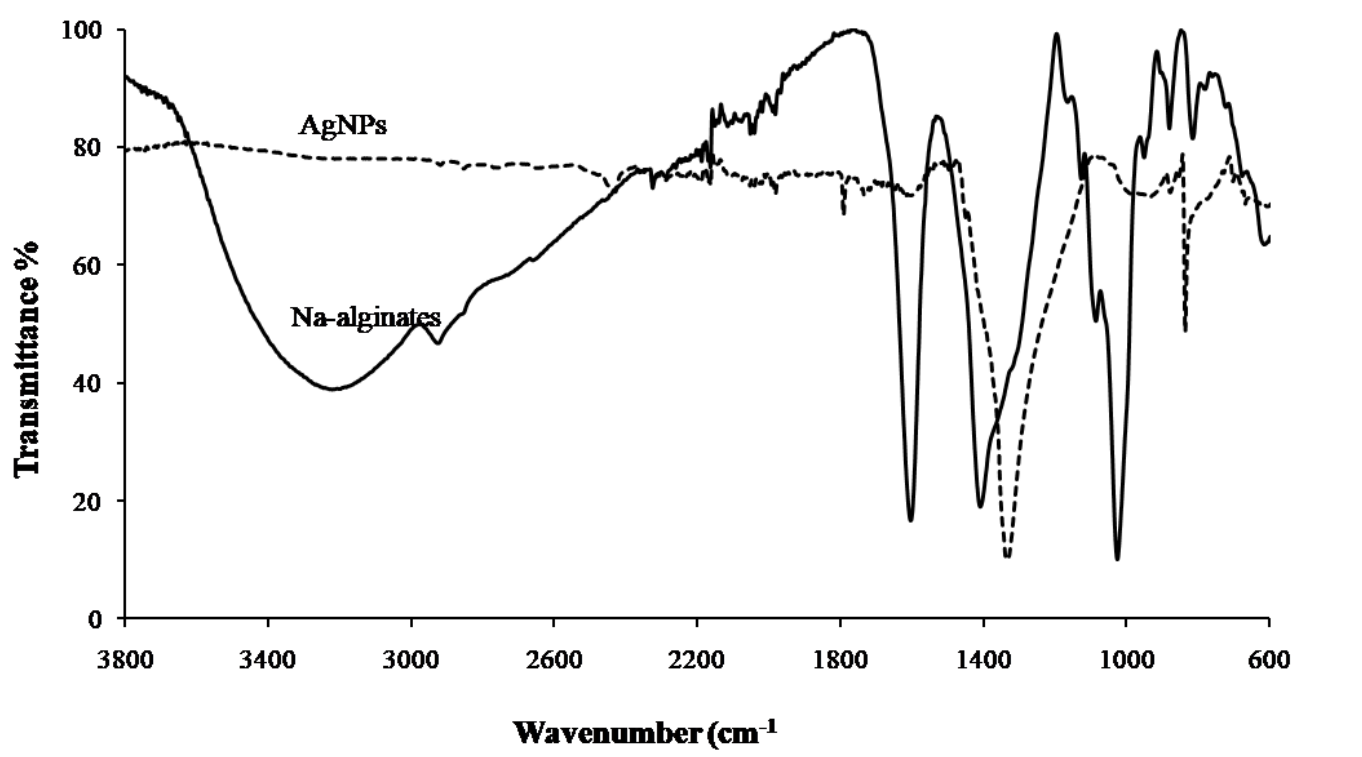

Figure 6. FTIR spectra of Laminaria ochroleuca Na-alginate and the synthesized AgNPs.

\subsection{Thermogravimetric Analysis.}

TGA curves of AgNPs and sodium alginate (Figure 7) depicted three main degradation steps. The initial slight weight loss $\left(100{ }^{\circ} \mathrm{C}\right)$ is due to moisture adsorbed on particles surface. After that, the main thermal degradation step was recorded between $120-220{ }^{\circ} \mathrm{C}$ for AgNPs, and it occurred between $120-280{ }^{\circ} \mathrm{C}$ for sodium alginate. During the third degradation step, the percentage of the residual mass decreased quietly to reach 35 and $70 \%$ at $700^{\circ} \mathrm{C}$ for sodium alginate and AgNPs, respectively. The synthesized nanoparticles appear to be thermally stable.

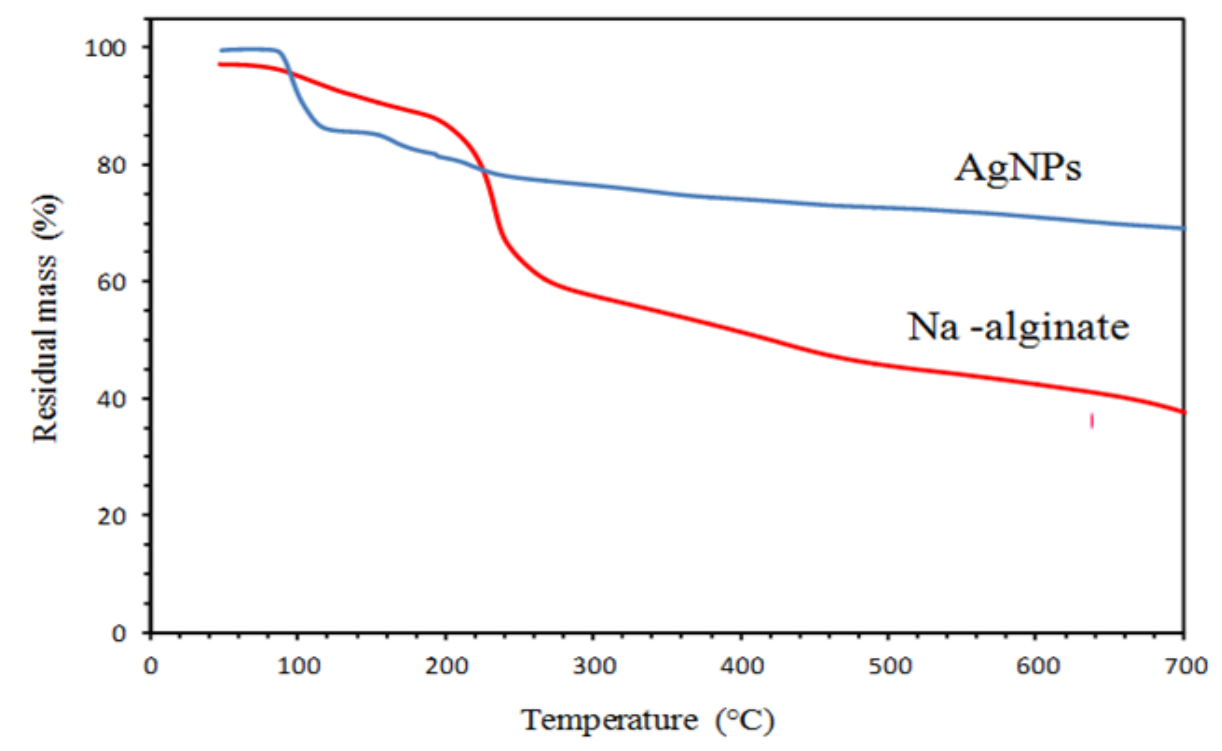

Figure 7. TGA curves of Laminaria ochroleuca Na-alginate and the synthesized AgNPs.

\subsection{Antibacterial properties.}

The antibacterial assay was tested against different human pathogenic strains of Gramnegative bacteria (Escherichia coli, Pseudomonas aeruginosa, Klebsiella pneumonia) and Gram-positive bacteria (Staphylococcus aureus, Bacillus cereus, and Micrococcus luteus). It is apparent that the synthesized nanoparticles showed important inhibition zones against two 
of the tested bacterial microorganisms, Gram-negative $K$. pneumonia and Gram-positive $S$. aureus (Table 1).

A maximum zone of inhibition was detected against Gram-positive $S$. aureus $(21 \mathrm{~mm})$ and a minimum zone of inhibition was obtained against Gram-negative E. coli (15 mm), while no inhibition zone appeared for the rest of the tested pathogenic strains. This might be explained by the large contact areas of small-sized synthesized AgNPs [40] and the different structure and composition of the cell wall in both bacteria types [41, 42]. Gram-negative bacteria with their thick peptidoglycan layer allow the entrance of only macromolecules. In contrast, the thinner layer of peptidoglycan and the abundant pores existing in the cell wall of Gram-positive bacteria allow foreign molecules to penetrate easily. This contributes to facilitating the absorption of the AgNPs into the bacterial cytoplasm, which leads to the disruption of its membrane, loss of cytoplasmic constituents, and ultimately cell death [43]. Additionally, Gram-positive bacteria have a high negative charge on the cell wall surface which possibly improves the antibacterial activity by attracting NPs [44]. Thus, the inhibition of the microbial processes could be made in the cell and on its surface. As reported in Kvitek et al. [45], nanoparticles may attach to the surface of the bacterial membrane, influencing the shape and function of the cell membrane and the disturbance of the bacteria respiration and permeability functions. AgNPs could also penetrate the bacteria to prevent protein synthesis and DNA replication through interaction with phosphorus-containing molecules [46], generating Reactive Oxygen Species by deactivating cellular enzymes [47].

Table 1. Antibacterial activity of biosynthesized silver nanoparticles compared with literature data.

\begin{tabular}{|c|c|c|c|c|c|c|c|}
\hline & \multicolumn{6}{|c|}{ Zone of inhibition $^{1}(\mathrm{~mm})$} & \multirow[b]{2}{*}{ References } \\
\hline & 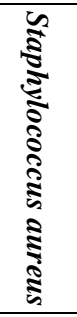 & 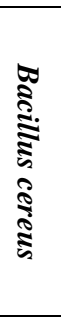 & 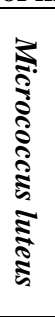 & 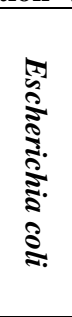 & 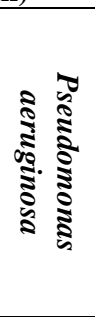 & 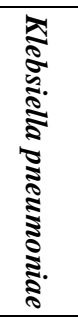 & \\
\hline AgNPs -Caulerpa serrulata extract & 16 & $\mathrm{nt}$ & $\mathrm{nt}$ & 21 & 14 & $\mathrm{nt}$ & [48] \\
\hline AgNPs -Caulerpa racemosa extract & 12 & nt & $\mathrm{nt}$ & $\mathrm{nt}$ & $\mathrm{nt}$ & $\mathrm{nt}$ & [49] \\
\hline AgNPs -Chlorella pyrenoidosa extract & 12 & nt & nt & nt & nt & 18 & [50] \\
\hline $\begin{array}{l}\text { AgNPs -Enteromorpha } \\
\text { flexuosa extract }\end{array}$ & 10 & nt & $\mathrm{nt}$ & 12 & 0 & 9 & {$[51]$} \\
\hline AgNPs -Pithophora oedogonia extract & 13.6 & nt & 15 & 16.8 & 17.2 & $\mathrm{nt}$ & {$[52]$} \\
\hline AgNPs -Sargassum ilicifolium extract & 16.8 & nt & $\mathrm{nt}$ & 18.2 & $\mathrm{nt}$ & 16.2 & [53] \\
\hline AgNPs - Sargassum muticum Na-alginate & 7 & 11 & 11 & 3 & 8 & 3 & [19] \\
\hline AgNPs - Padina tetrastromatica Na-alginate & 6 & nt & $\mathrm{nt}$ & $\mathrm{nt}$ & 4 & $\mathrm{nt}$ & [54] \\
\hline AgNPs - Laminaria ochroleuca Na-alginate & 21 & 0 & 0 & 15 & 0 & 0 & This study \\
\hline
\end{tabular}

${ }^{1}$ Zone of inhibition does not include the diameter of wells; nt: not tested

\section{Conclusions}

In the present study, an inexpensive, eco-friendly, and efficient method was developed for the green synthesis of silver nanoparticles (AgNPs).

Sodium alginate extracted from the kelp Laminaria ochroleuca from the Atlantic coast of Morocco was used as a stabilizing and reducing agent for the synthesis of the silver nanoparticles. Their characterization was determined by various analytical techniques such as 
UV-VIS spectroscopy, X-ray diffraction (XRD), Fourier transform infrared (FTIR) spectroscopy, transmission electron microscopy (TEM), TEM selected area electron diffraction (SAED), and thermogravimetric analysis (TGA).

The resulting particles exhibited interesting characteristics, including the spherical shape of the synthesized AgNPs, with maximum particles in the size range of 10-20 nm. The results also showed the face cubic centered (fcc) crystalline nature of the thermally stable synthesized silver nanoparticles (AgNPs). This study suggests that the synthesized silver nanoparticles possess significant antibacterial activity against Gram-negative and Grampositive bacteria. The use of Na-alginate extracted from Laminaria ochroleuca seems to be an interesting environmentally friendly procedure for synthesizing bioactive AgNPs, which makes it potentially interesting for medical uses.

\section{Funding}

This research was funded by the project VPMA3/DESRS-ANPMA-CNRST "Exploitation de la diversité spécifique et génétique pour une bioraffinerie innovante des algues marines de la côte atlantique marocaine".

\section{Acknowledgments}

We acknowledge the TEM national facility in Lille (France) supported by the Conseil Régional du Nord-Pas de Calais, the European Regional Development Fund (ERDF), and the Institut National des Sciences de l'Univers (INSU, CNRS). The Chevreul Institute is thanked for its help in the development of this work through the ARCHI-CM project supported by the "Ministère de l'Enseignement Supérieur de la Recherche et de l'Innovation", the region "Hautsde-France", the ERDF program of the European Union and the "Métropole Européenne de Lille".

\section{Conflicts of Interest}

The authors declare no conflict of interest

\section{References}

1. SI, A.; Pal, K.; Kralj, S.; El-Sayyad, G.S.; de Souza, F.G.; Narayanan, T. Sustainable preparation of gold nanoparticles via green chemistry approach for biogenic applications. Mater. Today Chem. 2020, 17, 100327, https://doi.org/10.1016/j.mtchem.2020.100327.

2. González-Ballesteros, N.; Rodríguez-Argüelles, M.C. Seaweeds: A promising bionanofactory for ecofriendly synthesis of gold and silver nanoparticles. Sustainable Seaweed Technologies 2020, Elsevier, 507-541, https://doi.org/10.1016/B978-0-12-817943-7.00018-4.

3. Dutta, D.; Das, B.M. Scope of green nanotechnology towards amalgamation of green chemistry for cleaner environment: A review on synthesis and applications of green nanoparticles. Environ. Nanotechnology, Monit. Manag. 2021, 15, 100418, https://doi.org/10.1016/j.enmm.2020.100418.

4. Anjali Das, C.G.; Kumar, V.G.; Dhas, T,S.; Karthick, V.; Govindaraju, K.; Joselin, J.M.; Baalamurugan, J. Antibacterial activity of silver nanoparticles (biosynthesis): A short review on recent advances. Biocatal. Agric. Biotechnol. 2020, 27, 101593, http://dx.doi.org/10.1016/j.bcab.2020.101593.

5. Govindan, P.; Murugan, M.; Pitchaikani, S.; Venkatachalam, P.; Gopalakrishnan, A.V.; Kandasamy, S.; Shakila, H. Synthesis and characterization of bioactive silver nanoparticles from red marine macroalgae Chondrococcus Hornemannii. Mater. Today Proc. 2021, https://doi.org/10.1016/j.matpr.2021.02.497.

6. Beyene, H.D.; Werkneh, A.A.; Bezabh, H.K.; Ambaye, T.G. Synthesis paradigm and applications of silver nanoparticles (AgNPs), a review. Sustain. Mater. Technol. 2017, 13, 18-23, 
https://doi.org/10.1016/j.susmat.2017.08.001.

7. Narayanan, M.; Devarajan, N.; He, Z.; Kandasamy, S.; Ashokkumar, V.; Raja, R.; Carvalho, I.S. Assessment of microbial diversity and enumeration of metal tolerant autochthonous bacteria from tailings of magnesite and bauxite mines. Mater. Today Proc. 2020, 33, 4391-4401, https://doi.org/10.1016/j.matpr.2020.07.652.

8. Mukherjee, S.; Sushma, V.; Patra, S.; Barui, A.K.; Bhadra, M.P.; Sreedhar, B.; Patra, C.R. Green chemistry approach for the synthesis and stabilization of biocompatible gold nanoparticles and their potential applications in cancer therapy. Nanotechnology 2012, 23, 455103, https://doi.org/10.1088/09574484/23/45/455103.

9. Valarmathi, N.; Ameen, F.; Almansob, A.; Kumar, P.; Arunprakash, S.; Govarthanan, M. Utilization of marine seaweed Spyridia filamentosa for silver nanoparticles synthesis and its clinical applications. Mater. Lett. 2020, 263, 127244, https://doi.org/10.1016/j.matlet.2019.127244.

10. Princy, K.F.; Gopinath, A. Green synthesis of silver nanoparticles using polar seaweed Fucus gardeneri and its catalytic efficacy in the reduction of nitrophenol. Polar Sci. 2021, 100692, https://doi.org/10.1016/j.polar.2021.100692.

11. Afshar, M.; Dini, G.; Vaezifar, S.; Mehdikhani, M.; Movahedi, B. Preparation and characterization of sodium alginate/polyvinyl alcohol hydrogel containing drug-loaded chitosan nanoparticles as a drug delivery system. J. Drug Deliv. Sci. Technol. 2020, 56, 101530, https://doi.org/10.1016/j.jddst.2020.101530.

12. Hasnain, M.S.; Nayak, A.K.; Kurakula, M.; Hoda, M.N. Alginate nanoparticles in drug delivery. Alginates in Drug Delivery 2020, Academic Press, Elsevier, 129-152, https://doi.org/10.1016/C2018-0-02298-7.

13. Chen, K.; Wang, F.; Liu, S.; Wu, X.; Xu, L.; Zhang, D. In situ reduction of silver nanoparticles by sodium alginate to obtain silver-loaded composite wound dressing with enhanced mechanical and antimicrobial property. Int. J. Biol. Macromol. 2020, 148, 501-509, https://doi.org/10.1016/j.ijbiomac.2020.01.156.

14. Hussanan, A.; Qasim, M.; Chen, Z-M. Heat transfer enhancement in sodium alginate based magnetic and non-magnetic nanoparticles mixture hybrid nanofluid. Phys. A Stat. Mech. and its Appl. 2020, 550, 123957, https://doi.org/10.1016/j.physa.2019.123957.

15. Lian, Y.; Wang, X.; Guo, P.; Li, Y.; Raza, F.; Su, J.; Qiu, M. Erythrocyte Membrane-Coated Arsenic Trioxide-Loaded Sodium Alginate Nanoparticles for Tumor Therapy. Pharmaceutics 2019, 12, 21, https://doi.org/10.3390/pharmaceutics12010021.

16. Saravanakumar, K.; Sathiyaseelan, A.; Mariadoss, A.V.A.; Xiaowen, H.; Wang, M-H. Physical and bioactivities of biopolymeric films incorporated with cellulose, sodium alginate and copper oxide nanoparticles for food packaging application. Int. J. Biol. Macromol. 2020, 153, 207-214, https://doi.org/10.1016/j.ijbiomac.2020.02.250.

17. Pérez, C.; Paul, M.; Bazerque, P. An Antibiotic assay by the agar well diffusion method. Acta Biologiae et Medicinae Experimentalis 1990, 15, 113-115.

18. Subrahamaniam, Y.; Mazlan, N.; Hassan, H.; Jaafar, J.N.; Anua, S.M.; Saud, S.N. Antimicrobial Activity of Musa acuminata Peel Extract against Gram-Positive Bacteria. Int. J. Life Sci. Biotechnol. 2020, 3, 191-196, http://dx.doi.org/10.38001/ijlsb.747883.

19. Belattmania, Z.; Bentiss, F.; Jama, C.; Barakate, M.; Katif, C.; Reani, A.; Sabour, B. Biosynthesis and Characterization of Silver Nanoparticles Using Sodium Alginate from the Invasive Macroalga Sargassum muticum. BioNanoScience 2018, 8, 617-623, https://link.springer.com/article/10.1007/s12668-018-0518-3.

20. Yugay, Y.A.; Usoltseva, R.V.; Silant'ev, V.E.; Egorova, A.E.; Karabtsov, A.A.; Kumeiko, V.V.; Ermakova, S.P.; Bulgakov, V.P.; Shkryl, Y.N. Synthesis of bioactive silver nanoparticles using alginate, fucoidan and laminaran from brown algae as a reducing and stabilizing agent. Carbohydr. Polym. 2020, 245, 116547, https://doi.org/10.1016/j.carbpol.2020.116547.

21. Shankar, S.S.; Rai, A.; Ahmad, A.; Sastry, M. Rapid synthesis of Au, Ag, and bimetallic Au core-Ag shell nanoparticles using Neem (Azadirachta indica) leaf broth. J. Colloid Interface Sci. 2004, 275, 496-502, https://doi.org/10.1016/j.jcis.2004.03.003.

22. Prasad, T.N.V.K. V.; Kambala, V.S.R.; Naidu, R. Phyconanotechnology: synthesis of silver nanoparticles using brown marine algae Cystophora moniliformis and their characterisation. J. Appl. Phycol. 2013, 25, 177-182, http://dx.doi.org/10.1007/s10811-012-9851-z.

23. Rao, Y.N.; Banerjee, D.; Datta, A.; Das, S.K.; Guin, R.; Saha, A. Gamma irradiation route to synthesis of highly re-dispersible natural polymer capped silver nanoparticles. Radiat. Phys. Chem. 2010, 79, 1240-1246, https://doi.org/10.1016/j.radphyschem.2010.07.004.

24. Yonezawa, Y.; Sato, T.; Ohno, M.; Hada, H. Photochemical formation of colloidal metals. J. Chem. Soc., Faraday Trans. 1: Phys. Chem. Condens. Phases 1987, 83, 1559-1567, 
https://doi.org/10.1039/F19878301559.

25. Yang, J.; Pan, J. Hydrothermal synthesis of silver nanoparticles by sodium alginate and their applications in surface-enhanced Raman scattering and catalysis. Acta Mater. 2012, 60, 4753-4758, https://doi.org/10.1016/j.actamat.2012.05.037.

26. Dhas, T.S.; Kumar, V.G.; Karthick, V.; Govindaraju, K.; Shankara Narayana, T. Biosynthesis of gold nanoparticles using Sargassum swartzii and its cytotoxicity effect on HeLa cells. Spectrochim. Acta Part A: Mol. Biomol. Spectrosc. 2014, 133, 102-106, https://doi.org/10.1016/j.saa.2014.05.042.

27. Joye, I.J.; McClements, D.J. Biopolymer-based nanoparticles and microparticles: Fabrication, characterization, and application. Curr. Opin. Colloid Interface Sci. 2014, 19, 417-427, https://doi.org/10.1016/j.cocis.2014.07.002.

28. Zhao, X.; Xia, Y.; Li, Q.; Ma, X.; Quan, F.; Geng, C.; Han, Z. Microwave-assisted synthesis of silver nanoparticles using sodium alginate and their antibacterial activity. Colloids and Surfaces A: Physicochem. And Eng. Asp. 2014, 444, 180-188, https://doi.org/10.1016/j.colsurfa.2013.12.008.

29. Montaser, A.S.; Jlassi, K.; Ramadan, M.A.; Sleem, A.A.; Attia, M.F. Alginate, gelatin, and carboxymethyl cellulose coated nonwoven fabrics containing antimicrobial AgNPs for skin wound healing in rats. Int. J. Biol. Macromol. 2021, 173, 203-210, https://doi.org/10.1016/j.ijbiomac.2021.01.123.

30. Sundarrajan, P.; Eswaran, P.; Marimuthu, A.; Subhadra, L.B.; Kannaiyan, P. One Pot Synthesis and Characterization of Alginate Stabilized Semiconductor Nanoparticles. Bull. Korean Chem. Soc. 2012, 33, 3218-3224, http://dx.doi.org/10.5012/bkcs.2012.33.10.3218.

31. Tripathi, R.; Mishra, B. "Development and Evaluation of Sodium Alginate-Polyacrylamide Graft-Copolymer-Based Stomach Targeted Hydrogels of Famotidine." AAPS PharmSciTech 2012, 13, 1091-1102, https://doi.org/10.1208/s12249-012-9824-1.

32. Rajivgandhi, G.N.; Ramachandran, G.; Maruthupandy, M.; Manoharan, N.; Alharbi, N.S.; Kadaikunnan, S.; Khaled, J.M.; Almanaa, T.N.; Li, W-J. Antioxidant, antibacterial and anti-biofilm activity of biosynthesized silver nanoparticles using Gracilaria corticata against biofilm producing K. pneumoniae. Colloids Surfaces A: Physicochem. And Eng. Asp. 2020, 600, 124830, https://doi.org/10.1016/j.colsurfa.2020.124830.

33. Voo, W-P.; Lee, B-B.; Idris, A.; Islam, A.; Tey, B-T.; Chan, E-S. Production of ultra-high concentration calcium alginate beads with prolonged dissolution profile. RSC Adv. 2015, 5, 36687-36695, https://doi.org/10.1039/C5RA03862F.

34. Mathlouthi, M.; Koenig, J.L. Vibrational Spectra of Carbohydrates. Advances in Carbohydrate Chemistry and Biochemistry 1987, 44, 7-89, Elsevier, https://doi.org/10.1016/S0065-2318(08)60077-3.

35. Silverstein R.M.; Clayton Bassler, G.; Morrill, T.C. Spectrometric identification of organic compounds $\left(5^{\text {th }}\right.$ Edition) 1991, Wiley.

36. Fenoradosoa, T.A.; Ali, G.; Delattre, C.; Laroche, C.; Petit, E.; Wadouachi, A.; Michaud, P. Extraction and characterization of an alginate from the brown seaweed Sargassum turbinarioides Grunow. J. Appl. Phycol. 2010, 22, 131-137, http://dx.doi.org/10.1007/s10811-009-9432-y.

37. Leal, D.; Matsuhiro, B.; Rossi, M.; Caruso, F. FT-IR spectra of alginic acid block fractions in three species of brown seaweeds. Carbohydr. Res. 2008, 343, 308-316, https://doi.org/10.1016/j.carres.2007.10.016.

38. Lawrie, G.; Keen, I.; Drew, B.; Chandler-Temple, A.; Rintoul, L.; Fredericks, P.; Grøndahl, L. Interactions between Alginate and Chitosan Biopolymers Characterized Using FTIR and XPS. Biomacromolecules 2007, 8, 2533-2541, https://doi.org/10.1021/bm070014y.

39. Gómez-Ordóñez, E.; Rupérez, P. FTIR-ATR spectroscopy as a tool for polysaccharide identification in edible brown and red seaweeds. Food Hydrocoll. 2011, 25, 1514-1520, https://doi.org/10.1016/j.foodhyd.2011.02.009.

40. Baker, C.; Pradhan, A.; Pakstis, L.; Pochan, D.; Shah, S.I. Synthesis and Antibacterial Properties of Silver Nanoparticles. J. Nanosci. Nanotechnol. 2005, 5, 244-249, https://doi.org/10.1166/jnn.2005.034.

41. Yu, J.; Zhang, W.; Li, Y.; Wang, G.; Yang, L.; Jin, J.; Chen, Q.; Huang, M. Synthesis, characterization, antimicrobial activity and mechanism of a novel hydroxyapatite whisker/nano zinc oxide biomaterial. Biomed. Mater. 2014, 10, 15001, https://doi.org/10.1088/1748-6041/10/1/015001.

42. Guzman, M.; Dille, J.; Godet, S. Synthesis and antibacterial activity of silver nanoparticles against grampositive and gram-negative bacteria. Nanomedicine: Nanotechnology, Biol. And Med. 2012, 8, 37-45, https://doi.org/10.1016/j.nano.2011.05.007.

43. Wang, L.; Hu, C.; Shao, L. The antimicrobial activity of nanoparticles: present situation and prospects for the future. Int. J. Nanomedicine 2017, 12, 1227-1249, https://doi.org/10.2147/IJN.S121956.

44. Sarwar, A.; Katas, H.; Samsudin, S.N.; Zin, N.M. Regioselective Sequential Modification of Chitosan via 
Azide-Alkyne Click Reaction: Synthesis, Characterization, and Antimicrobial Activity of Chitosan Derivatives and Nanoparticles. PLoS One 2015, 10, e0123084, https://doi.org/10.1371/journal.pone.0123084.

45. Kvítek, L.; Prucek, R.; Panáček, A.; Novotný, R.; Hrbáč, J.; Zbořil, R. The influence of complexing agent concentration on particle size in the process of SERS active silver colloid synthesis. J. Mater. Chem. 2005, 15, 1099-1105, http://dx.doi.org/10.1039/B417007E.

46. Morones, J.R.; Elechiguerra, J.L.; Camacho, A.; Holt, K.; Kouri, J.B.; Ramírez, J.T.; Yacaman, M.J. The bactericidal effect of silver nanoparticles. Nanotechnology 2005, 16, 2346-2353, https://doi.org/10.1088/0957-4484/16/10/059.

47. Sahayaraj, K.; Sathiyamoorthy, R.; Rathi, J.M. Silver nanoparticles biosynthesis using marine algae Padina pavonica (Linn.) and its microbial activity. Dig. J. Nanomater. Biostructures 2012, 7, 1557-1567.

48. Aboelfetoh, E.F.; El-Shenody, R.A.; Ghobara, M.M. Eco-friendly synthesis of silver nanoparticles using green algae (Caulerpa serrulata): reaction optimization, catalytic and antibacterial activities. Environ. Monit. Assess. 2017, 189, 349, https://doi.org/10.1007/s10661-017-6033-0.

49. Kathiraven, T.; Sundaramanickam, A.; Shanmugam, N.; Balasubramanian, T. Green synthesis of silver nanoparticles using marine algae Caulerpa racemosa and their antibacterial activity against some human pathogens. Appl. Nanosci. 2015, 5, 499-504, http://dx.doi.org/10.1007/s13204-014-0341-2.

50. Aziz, N.; Faraz, M.; Pandey, R.; Shakir, M.; Fatma, T.; Varma, A.; Barman, I.; Prasad, R. Facile AlgaeDerived Route to Biogenic Silver Nanoparticles: Synthesis, Antibacterial, and Photocatalytic Properties. Langmuir 2015, 31, 11605-11612, http://dx.doi.org/10.1021/acs.langmuir.5b03081.

51. Yousefzadi, M.; Rahimi, Z.; Ghafori, V. The green synthesis, characterization and antimicrobial activities of silver nanoparticles synthesized from green alga Enteromorpha flexuosa (wulfen) J. Agardh. Mater. Lett. 2014, 137, 1-4, https://doi.org/10.1016/j.matlet.2014.08.110.

52. Sinha, S.N.; Paul, D.; Halder, N.; Sengupta, D.; Patra, S.K. Green synthesis of silver nanoparticles using fresh water green alga Pithophora oedogonia (Mont.) Wittrock and evaluation of their antibacterial activity. Appl. Nanosci. 2015, 5, 703-709, https://doi.org/10.1007/s13204-014-0366-6.

53. Kumar, P.; Selvi, S.S.; Prabha, L.; Selvaraj, M.; Rani, L.; Palanisamy, S.; Boominathan, S.D.; Munisamy, G. Antibacterial activity and in-vitro cytotoxicity assay against brine shrimp using silver nanoparticles synthesized from Sargassum ilicifolium. Dig. J. Nanomater. Biostructures 2012, 7, 1447-1455.

54. Sangeetha, N.; Manikandan, S.; Singh, Manoj; Kumaraguru, A.K. Biosynthesis and Characterization of Silver Nanoparticles Using Freshly Extracted Sodium Alginate from the Seaweed Padina tetrastromatica of Gulf of Mannar, India. Curr. Nanosci. 2012, 8, 697-702, http://dx.doi.org/10.2174/157341312802884328. 